\title{
The clinically important impact of preschool oral immunotherapy on parental quality of life
}

Rishma Chooniedass ${ }^{1}$, Alexandra Baaske ${ }^{2}$, Sandeep Kapur ${ }^{3}$, Mary McHenry ${ }^{3}$, Victoria Cook $^{4}$, Scott Cameron ${ }^{2}$, Thomas Gerstner ${ }^{5}$, Tiffany Wong ${ }^{2}$, Timothy Vander Leek ${ }^{6}$, Raymond $\mathrm{Mak}^{4}$, Stephanie Erdle ${ }^{7}$, Rory Lynn Cunada ${ }^{2}$, Edmond Chan $^{2}$, and Lianne Soller ${ }^{2}$

${ }^{1}$ The University of British Columbia

${ }^{2}$ BC Children's Hospital

${ }^{3}$ Dalhousie University

${ }^{4}$ The University of British Columbia Faculty of Medicine

${ }^{5}$ University of Manitoba

${ }^{6}$ University of Alberta

${ }^{7}$ British Columbia Children's Hospital

October 31, 2021

\section{Hosted file}

Impact of preschool OIT on QoL_final version.docx available at https://authorea.com/users/ 443773/articles/543700-the-clinically-important-impact-of-preschool-oral-immunotherapyon-parental-quality-of-life 